\title{
A Mathematical Model to Investigate Heat Transfer in Footwear during Walking and Jogging
}

\author{
H. Nemati ${ }^{1}$, M.A. Moghimi ${ }^{2}$, Roozbeh Naemi ${ }^{3}$ \\ ${ }^{1}$ Department of Mechanics, Marvdasht Branch, Islamic Azad University, Marvdasht, Iran. \\ Corresponding Author: H.Nemati@miau.ac.ir \\ ${ }^{2}$ Department of Design and Engineering, Staffordshire University, Stoke-On-Trent ST4 2DE, UK. \\ ${ }^{3}$ Centre for Biomechanics and Rehabilitation Technologies Staffordshire University, Leek Road, Stoke on Trent ST4 2DF, \\ UK
}

\begin{abstract}
Foot temperature during activities of daily living affects the human performance and well-being. Footwear thermal characteristics affect the foot temperature inside the shoe during activities of daily living. The temperate at the sole of the foot (plantar temperature) is influenced by different thermal properties such as heat capacity, heat diffusivity, and thermal conductivity of the shoe sole in addition to its mechanical properties. Hence the purpose of this study was to propose a method to allow investigating the effect of footwear thermal characteristics on the foot temperature during activities of daily living, like walking or jogging.

The transient heat transfer between the foot and the ground was studied to drive the governing equation for heat transfer modelling in footwear and to predict foot sole temperature during walking, and jogging. Different thermo-mechanical properties of shoe sole, as well as geometrical parameters, were investigated. The proposed model showed to be able to adequately predict the plantar temperature at the ball of the foot when compared to the results from experimental measurements. Finally, using the proposed method, the thermal behaviour of two different shoes with two different sole materials EVA08 and EVA12 were compared. It was shown that heat capacity as compared to the thermal conductivity of the shoe sole is more effective in reducing the plantar temperature increase in short term. The proposed method proved to be able to accurately predict the thermal behaviour of shoes and can provide a tool to predict footwear thermal comfort.
\end{abstract}

Keywords: Footwear, Thermal comfort, Heat transfer, Foot sole temperature, Plantar soft tissue

\section{Introduction}


Footwear design has commonly had a general focus on aesthetics and comfort with specific attention to fit and cushioning characteristics. More recently, there have been a number of studies in which the thermal characteristics of the footwear have been considered (Havenith et al., 2013; Kopitar et al., 2019; Puszkarz and Usupov, 2019; Shimazaki et al., 2016; Shimazaki and Murata, 2015). There are several studies with a focus on assessing footwear heat transfer performance in the extremely cold environment (Covill et al., 2008; Covill et al., 2011; Havenith et al., 2013; Kopitar et al., 2019; Rintamäki et al., 2004). In those studies, generally, the thermal insulation was applied for the shoe sole which physically indicates that the amount of heat loss from the foot sole to the environment is significantly reduced. On the other hand, there is a consensus that a human foot acts as a thermal radiator for the body (Taylor et al., 2014). Therefore, cooling the feet is another important factor for footwear performance in various applications, e.g. during sports activities whereas as a result of intense activities, blood circulation would significantly increase and consequently, the excess energy is dissipated from the feet. However, since feet are enclosed within shoes, dissipating this excess heat to the environment is challenging, leading to excess sweat which cause bacteria growth and consequently lead to foot odour.

In a previous study midsole temperature of greater than $50{ }^{\circ} \mathrm{C}$ was reported in running during summer daytime (Kinoshita and Bates, 1996). In these conditions, maintaining the body temperature between 34 and $40^{\circ} \mathrm{C}$ would be challenging because the human body even at peak mechanical efficiency, dissipates $75-80 \%$ of the muscular energy into heat (James, 1999). This indicates that thermal management of shoe and its thermal comfort are crucial factors that should be considered during shoe designs.

As thermal comfort mainly depends on skin temperature (Bulcao et al., 2000), footwear thermal comfort is more related to increased foot temperature than being relevant to moisture retention (Arezes et al., 2013). In that regard, several experimental works were conducted on foot sole temperature measurement (Carbonell et al., 2019; Kuklane, 2004; Puszkarz and 
Usupov, 2019; Shimazaki et al., 2016; Shimazaki and Murata, 2015; Taiar et al., 2013). While some studies were conducted via measuring foot temperature in multiple footwear designs over a period of time, some others relied on time-consuming CAE (Computer-aided Engineering) simulations. For example, Puszkarz and Usupov (Puszkarz and Usupov, 2019) placed a rubber container filled with water at a temperature of $35{ }^{\circ} \mathrm{C}$ inside the shoe and measured the temperature of the shoe surface using a thermal imaging camera and compared results against the results of Finite Element Method (FEM) simulation. A good agreement between numerical and experimental data were reported (Puszkarz and Usupov, 2019), where similar experiments were performed by Dessing et al. (Dessing et al., 2014). Regardless of all valuable reported measurements in previous studies, experimental and numerical studies will require access to physical and computational resources (i.e. large numbers of data collection, or huge processing power or complex models) which may not be always available. In addition, experimental studies are time consuming and expensive, while analytical approaches can provide an insightful assessment in a relatively short time with minimum resources. This feature of analytical methods along with their ability is assessing wide range of parameters including the properties of the footwears can be considered as unique advantages of these methods. The main advantage of analytical method is its ability to reveal the relationship between the foot sole temperature and the influential factors which will be very important for future experiments and shoe design.

These features justify assessing the footwear heat transfer characteristics during activities of daily living which have been rarely considered. Indeed, the majority of conducted studies in this field have either used experimental or finite element analyses (Covill et al., 2011; Dessing et al., 2014; Puszkarz and Usupov, 2019; Rebay et al., 2007; Shimazaki and Murata, 2015). While analytical models have been previously developed to assess the force deformation relationship during foot-ground interactions (Naemi et al., 2016; Naemi and 
Chockalingam, 2013a, b), there is currently no analytical model available for the assessment of heat transfer in footwear sole.

The objective of this study was to develop a reliable and validated practical model that can be used to predict the temperature at the sole of the foot (plantar temperature) during the shod walking or jogging condition. Upon development, the mathematical model can allow quantifying heat transfer between the foot and the ground during shod condition. This could potentially be a very useful tool for scientists, manufacturers, and for clinicians who deal with patients with prolong diseases.

\section{Method and requirements}

To provide comprehensive mathematical modelling for foot thermal assessment, two different scenarios were investigated in this study. In the first scenario, the foot temperature of a person in shod condition, while sitting or standing still for long time was investigated. This scenario is called the standstill condition. While the focus of this study is on heat transfer during activities such as walking or jogging, the standstill scenario is still necessary as the initial condition of the second scenario. The second scenario was designated to simulate the foot temperature in the shod condition during walking/jogging at different speeds. In this scenario, the model includes the thermo-mechanical interaction between shoe sole and foot.

Prior to presenting the thermal modelling of the proposed scenarios initially, preliminary studies on the dominant conditions of stepping procedure including thermo-mechanical effect of the shoe are presented. These preliminary studies will be reported in section 2 as the stepping stones of the modelling for the discussed scenarios (standstill and walking/jogging scenarios). In section 3, assumptions of each scenario are followed by its governing equations and its analytical solutions. The obtained results of the models (presented in section 4) are validated in section 4 against experimental data points for a wide range of jogging speed. 
Moreover, to show the applicability of results, the extracted formulas are applied to a different shoe sole material. The complementary discussions and conclusions are presented in section 5 and 6 , respectively.

\subsection{Preliminary Studies on the Thermal Conditions during Stepping Procedure}

Human walking is a complex activity in which the cyclic movements of the lower extremities translate the body in forward direction (Mochon and McMahon, 1980). From heat transfer point of view, there are two main distinctions between the standstill condition and walking/jogging scenario:

1) The heat extraction mechanism from the shoe, and

2) Existence of additional heat sources (e.g. thermo-mechanical shoe sole effect and or metabolism rate change) in the $2^{\text {nd }}$ scenario.

Fig. 1 shows a schematic cycle that a foot passes during walking/jogging activity. During this process, the contact of the shoe with the ground is alternatively changed (Fig. 1 a to c) and the loading and unloading of shoe sole lead to the generation of volumetric heat source in the shoe sole which affects the foot temperature (Fig. 1 d to e). Besides, as a person starts walking or jogging from the standstill condition, the metabolism rate of the body (as the main source of generated heat in the body) will vary with time. Therefore, analytical foot temperature prediction is a time-dependent problem in walking/jogging scenario against standstill scenario which is a steady-state problem. 


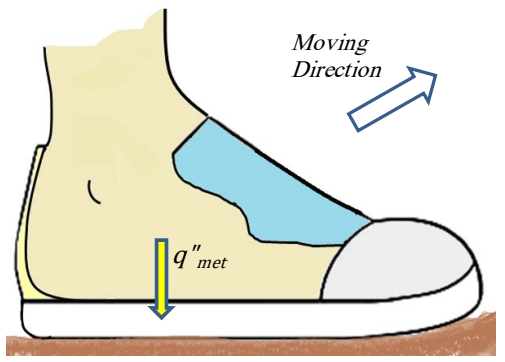

(a)

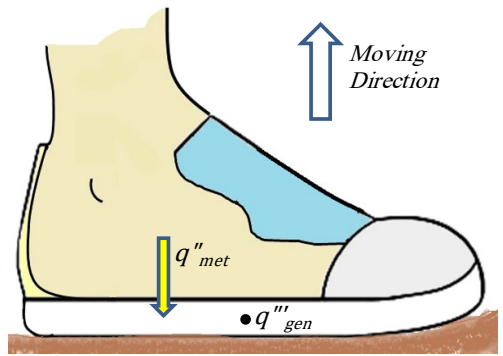

(f)

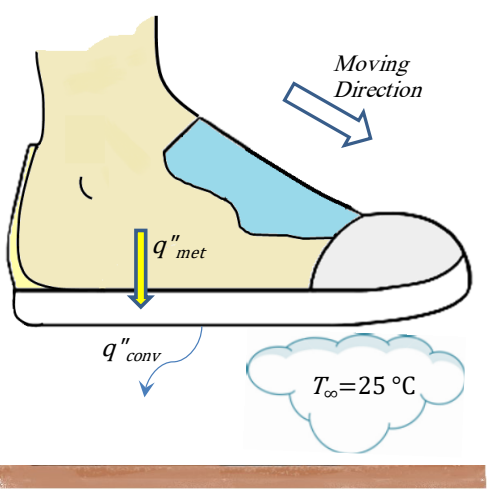

(b)

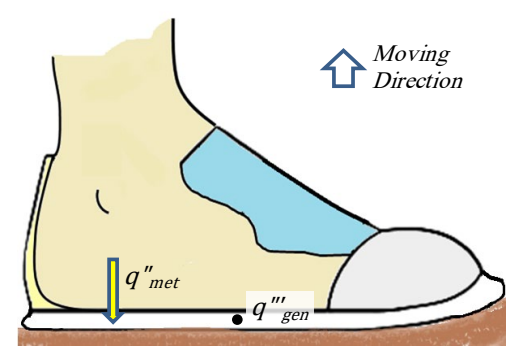

(e)

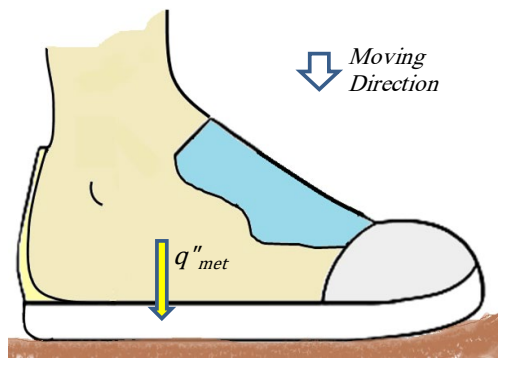

(c)

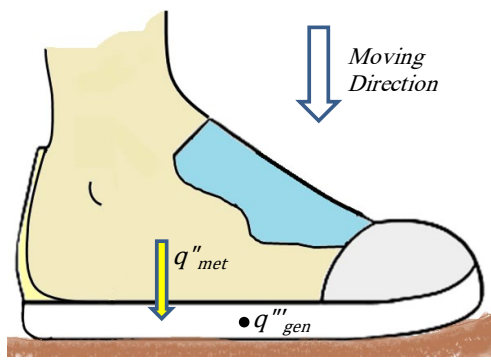

(d)

Fig. 1: A schematic cycle of an experience that a foot in shoe has during walking/jogging:

a) Detaching the shoe sole from the ground, it is no longer under compression (take-off moment), b) The stage that the shoe is in the air (swing stage) and is cooled by convection, c) The moment that the shoe sole just touches the ground (landing moment), however, the shoe sole is not under the load yet, d) The onset of shoe sole compression. This is the starting point of the generation of volumetric heat source in shoe sole due to viscous work in shoe sole, e) The foot sole is fully compressed $\mathrm{f}$ ) the foot starts to take off from the ground (decompression stage) until it reaches to its unloading condition. This would be the ending point of volumetric heat generation in shoe sole due to viscous work.

\subsection{Considering the cooling effect of the foot swinging in the air}

For accurate modelling of the walking/jogging scenario and to have a proper estimation of the foot temperature in a shoe during this activity, the following assumptions are considered:

- During the walking/jogging, as shown in Fig. 1, the contact of the exterior surface of the shoe sole with the ground is lost, and the forced convective heat transfer mechanism is 
much more efficient than conduction heat transfer between solid surfaces (shoe sole and ground, Fig. 1 a, and Fig. 1 c). Therefore, the heat on the external surface of the shoe sole is mainly dissipated to the environment by convection of air ( $q_{c o n v}^{\prime \prime}$ in Fig. $\left.1 \mathrm{~b}\right)$. In that regard, the persons walking/jogging velocity is considered as average velocity of air relative to a shoe (i.e. zero wind condition).

- It is assumed that during the walking and jogging activities the shoe sole is not bent (in other words it will be a flat surface during different phases of the activity as shown in Fig. 1).

Therefore, the average convective heat transfer coefficient $(h)$ can be calculated as (Bergman et al., 2011):

$h=0.037 \frac{k_{s}}{L} \operatorname{Re}^{4 / 5} \operatorname{Pr}^{1 / 3}$

$R e=\frac{\rho \cdot V \cdot L}{\mu}$

$\operatorname{Pr}=\frac{\mu \cdot c p}{k}$

\subsection{Considering the heat generation in shoe sole due to periodic loading-unloading condition}

During jogging, the shoe sole periodically experiences a loading-unloading condition (see Fig. 1 d-e). Since the shoe sole is made of viscoelastic materials (e.g. Polyurethane Elastomers, EVA foam, etc), under harmonic loading (as shown in Fig. 1 d-e), heat is generated inside the shoe sole $\left(q_{G e n}^{\prime \prime \prime}\right)$ due to the viscous behaviour of the sole.

Fig. 2 shows a sample of harmonic stress-strain response. The stress amplitude, $\sigma_{0}$, is the contact force divided by the average contact area. 


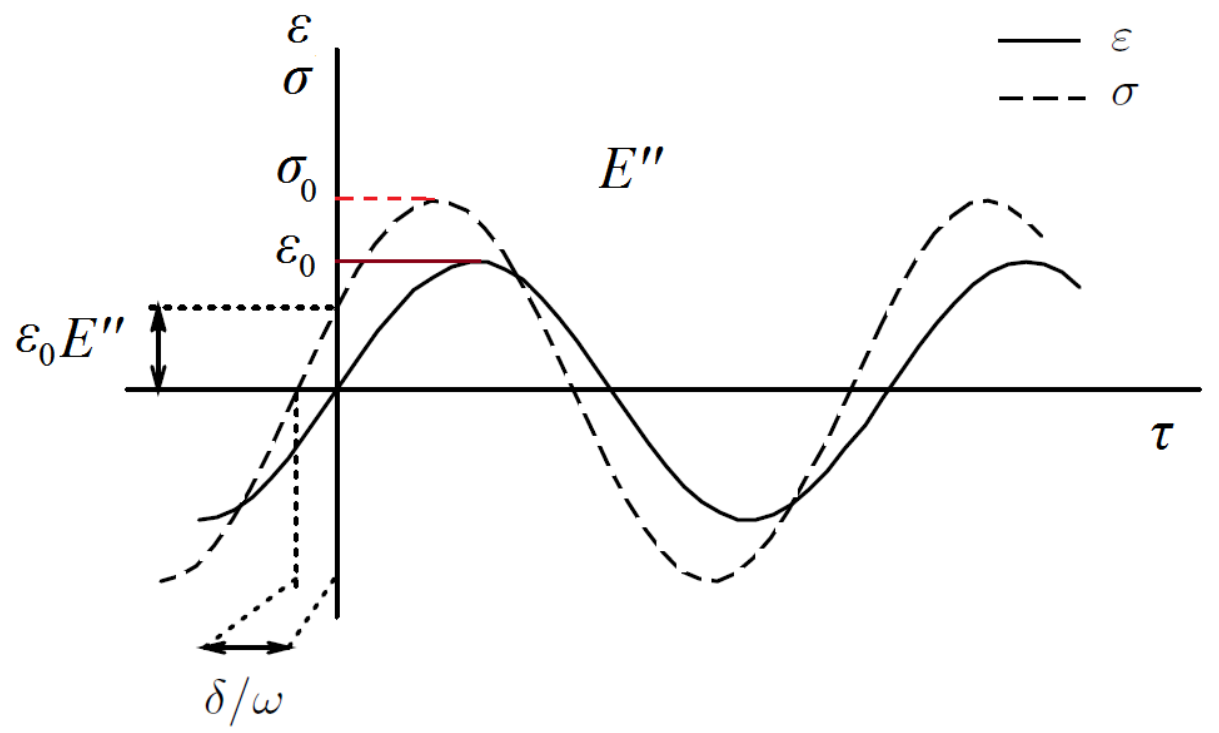

Fig. 2: Sample of harmonic strain excitation and stress response

For this harmonic pattern, the volumetric generated heat during one period of the harmonic strain excitation is (Schreurs, 2012):

$U_{d}=\pi \varepsilon_{0}^{2} E^{\prime \prime}$

$\varepsilon_{0}=\frac{\sigma_{0}}{\pi \sqrt{\left(E^{\prime \prime}\right)^{2}+\left(E^{\prime}\right)^{2}}}$

where $E^{\prime}, E^{\prime \prime}, \sigma_{0}$ and $\varepsilon_{0}$ are the storage modulus, loss modulus, stress amplitude, and strain amplitude respectively.

Walking in its turn is a harmonic motion. An example of the time-dependent gait motion pattern was reported by (Shimazaki and Murata, 2015) which is brought in Fig. 3. The contact force (the average force between the sole of foot and the shoe sole) is normalized by the person's weight. As shown in this figure, a harmonic pattern is observed in the contact force. The maximum contact force value depends on the gait speed and its value increases at higher speeds. It is important to note that at landing during running, the maximum contact force may be more than the body's weight (Chuckpaiwong et al., 2008). 


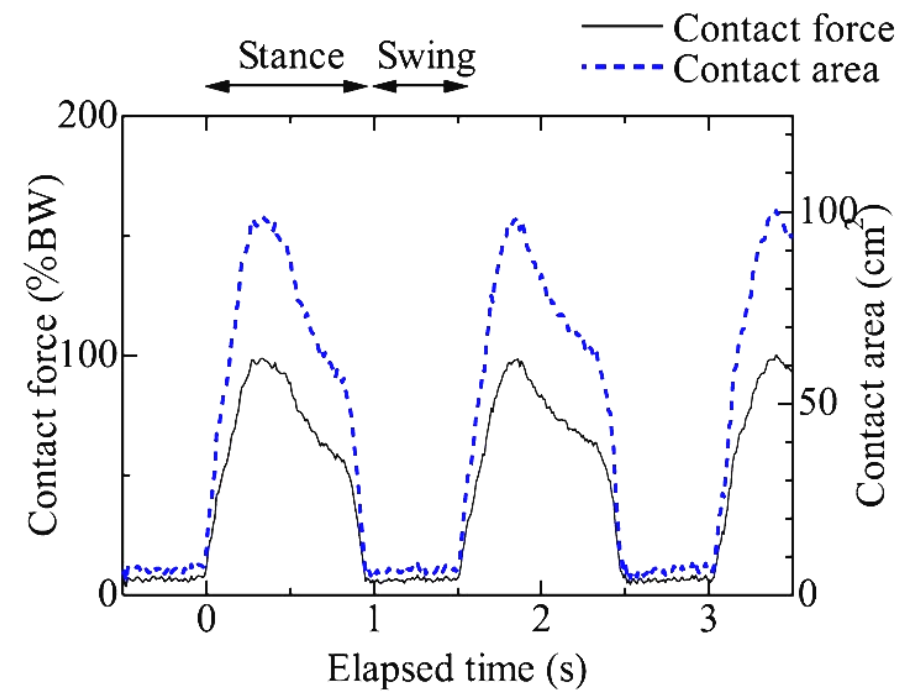

(a) $3.0 \mathrm{~km} / \mathrm{hr}$

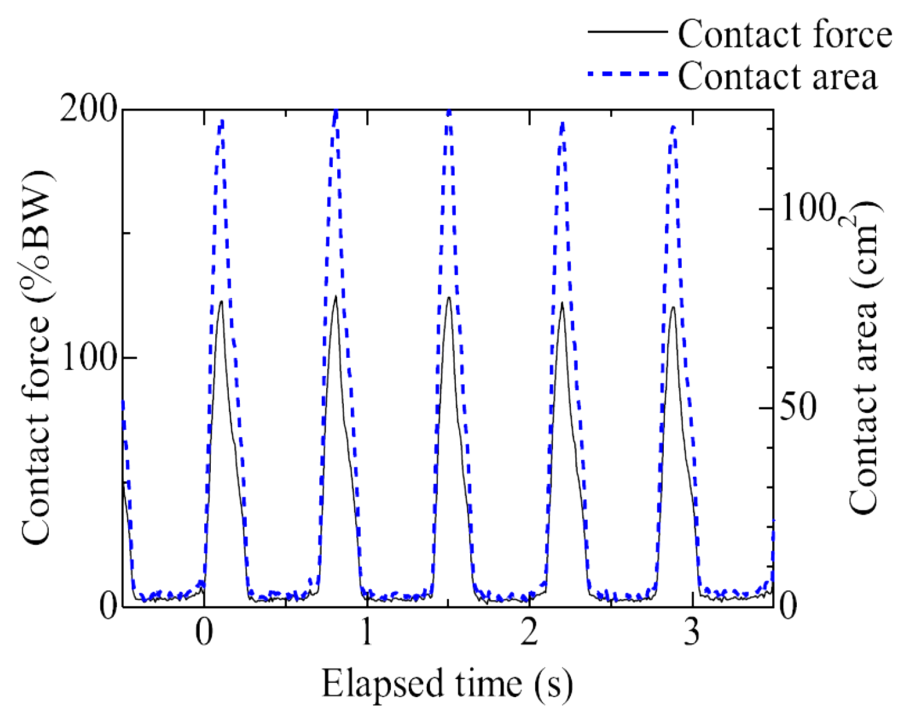

(a) $12.0 \mathrm{~km} / \mathrm{hr}$

Fig. 3: Time-dependent contact force and contact changes (Shimazaki and Murata, 2015).

The same trend is also considered for the contact area where this area is introduced as the foot sole average surface area that is in contact with the shoe sole (or ground) during walking. However, based on experimental evidence (Shimazaki and Murata, 2015), the average contact area is independent of gait speed. The values of the maximum contact force in variable gait speeds are listed in Table 1. 
Table 1: Maximum contact force in percent of Body Weight for different gait speeds (Shimazaki and Murata, 2015)

\begin{tabular}{cccc}
\hline Speed & 3 & 6 & 9 \\
$(\mathrm{~km} / \mathrm{hr})$ & & & \\
\hline Max. Contact force & 100 & 110 & 170 \\
$(\%$ B.W. $)$ & & & \\
\hline
\end{tabular}

considering the above explanation, the volumetric heat power can be obtained by dividing the volumetric generated heat (Eq. (3)) by the period time $\left(\tau_{\text {Stance }}+\tau_{\text {Swing }}\right)$ :

$q_{\text {Gen }}^{\prime \prime \prime}=\frac{U_{d}}{2\left(\tau_{\text {Stance }}+\tau_{\text {Swing }}\right)} \cdot \frac{A_{\text {cont }}}{A}$

Based on Fig. 2, a full period of a harmonic strain excitation consists of both compression and expansion periods while as shown in Fig. 3, the gait motion pattern only experiences a comparison section (only half of the harmonic cycle). Therefore factor 2 is considered in the denominator of Eq. (4). Moreover, since the contact area, $A_{\text {cont }}$, is less that heat transfer area (as it is explained in Fig. 3), the first ratio is multiplied by $\frac{A_{\text {cont }}}{A}$.

\subsection{Considering the metabolism change during walking/jogging}

Starting from the standstill condition to walking, the metabolism rate of the person can be approximated as a piecewise constant function, by considering $\tau_{1}$ as the cut-off time between jogging and recovery period as follows:

$q_{m e t}^{\prime \prime}(\tau)=\left\{\begin{array}{lll}F \cdot q_{\text {met } 0}^{\prime \prime} & \text { if } & \tau<\tau_{1} \\ q_{\text {met } 0}^{\prime \prime} & \text { if } & \tau \geq \tau_{1}\end{array}\right.$

This trend follows the physical findings of metabolism variation in literature. E.g. Shimazaki and Murata (Shimazaki and Murata, 2015) during a fifty-minute experimental measurement, including a ten-minute rest, followed by 30 minutes jogging $\left(\tau_{1}\right)$ and 10 minute recovery, the metabolism trend varies as follow:

- During the standing still period, the metabolism is almost constant (Eq. (8). 
- As jogging commenced it rises sharply and remains almost constant at the same level (Eq. (24)).

- $\quad$ During the recovery period, it gets back to its initial level (Eq. (8).

$q_{m e t 0}^{\prime \prime}$ is estimated by Eq. (8) and the metabolism rate increase factor is also estimated by Eq. (24) and will be explained in more detail, later.

\section{Heat transfer modelling of a foot in the shoe}

In this study, two scenarios are investigated thoroughly to model the thermo-mechanical interaction of shoe sole and foot. In the standstill scenario, this study attempts to find the foot temperature in shod condition during sitting and or standing still for a long period. The second scenario is designed to simulate the foot temperature of the same person as s/he starts walking or jogging from standstill condition with different speeds as discussed in more details in the following separate sections:

\subsection{Foot temperature prediction in standstill condition (wearing shoes with no long- term movement)}

Fig. 4 shows the schematic of the standstill condition. In this study, it was assumed that the person is wearing shoes for a long time in a standstill. This part of the study simulates daily routine activities such as sitting behind a desk or standing still. To model the standstill condition and calculate the heat transfer from the shoe, the following assumptions are considered:

- The ground temperature is assumed constant.

- As the person is in a standstill condition for a long time, the inner surface of the shoe sole and foot sole are assumed to be in thermal equilibrium. It means that the foot sole and inner surface of the shoe sole always have the same temperature.

- Long-time thermal equilibrium foot means that the foot temperature does not change with time. In other words, this scenario is a one-dimensional steady-state heat transfer problem. 
- In addition, since the person is in a standstill condition with no movement, one can assume that the foot sole is always in contact with the top side of the inner surface of the shoe sole (Fig. 4). Under this condition, conduction is the dominant heat transfer mechanism which means the generated heat due to metabolism is conducted from the foot sole to the ground via the shoe sole.

- No thermo-mechanical work of sole has been considered for the standstill condition which leads to no energy generation in shoe sole in this condition.

- Due to small variations in temperature, thermal properties are assumed constant and independent of temperature.

- $\quad$ The size of the shoe in this study is equal to 39-40 European size and or 9 US size which is equal to $26 \mathrm{~cm}$ in length. The only shoe properties which affect the foot temperature in the standstill condition are the sole material (thermal conductivity) and sole thickness.

- Foot with no socks is considered in the shoe.

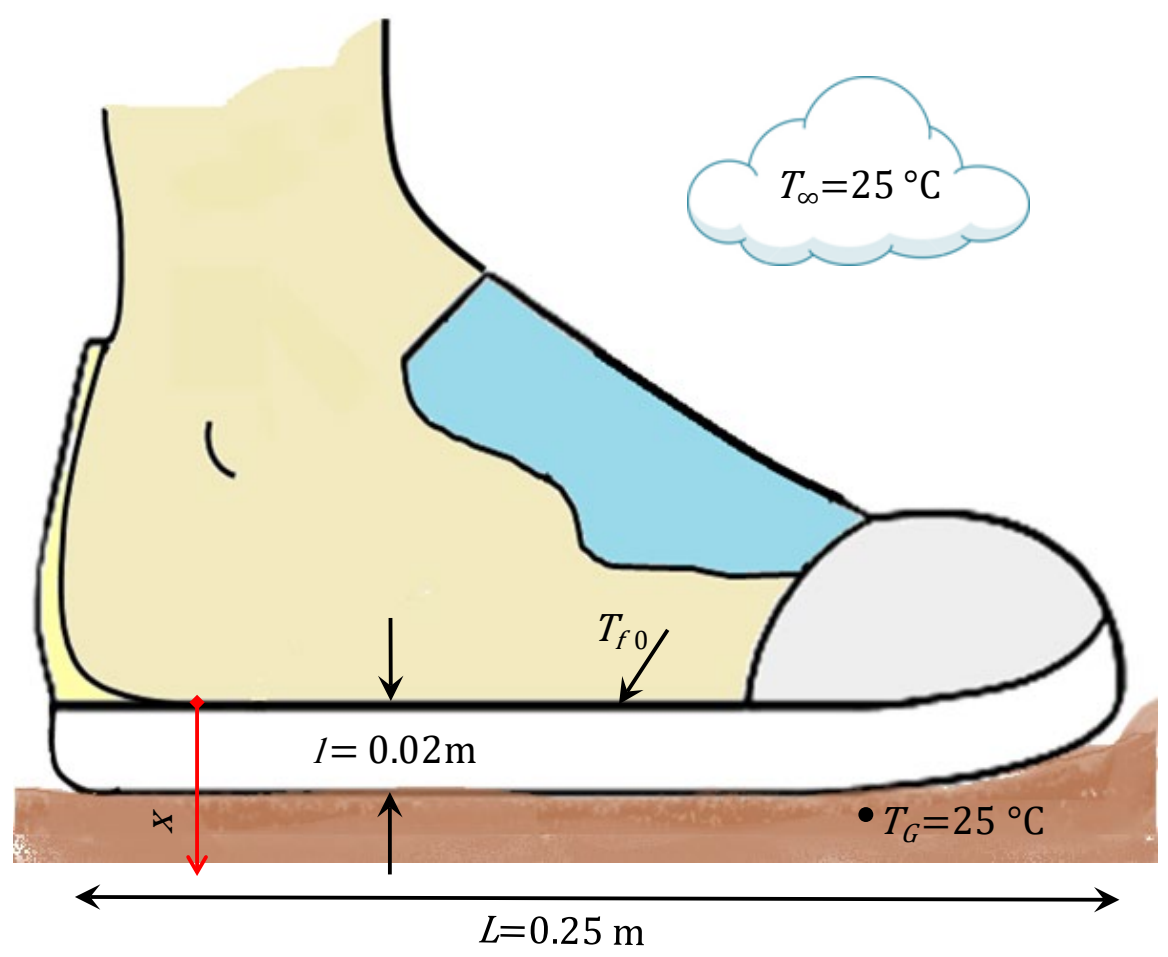

Fig. 4: The schematic of standstill condition 
With the above assumptions as the person is standstill, the governing equation (Hahn and Özisik, 2012) and the boundary conditions at the inner surface of shoe sole and the outer surface of the shoe sole are:

$k_{s} \frac{d^{2} T}{d T^{2}}=0$

$T(x=0)=T_{f 0}$

$T(x=l)=T_{G}$

where $k_{s}$ is the shoe sole thermal conductivity and $T$ is temperature. $l=0.02 \mathrm{~m}$ is the shoe sole thickness. $T_{f 0}=34{ }^{\circ} \mathrm{C}$ and $T_{G}=25^{\circ} \mathrm{C}$ are the foot sole and ground temperatures, respectively.

Since Eq. (6) is an ordinary differential equation, then the solution is:

$T(x)=\left(T_{\infty}-T_{f 0}\right) \frac{x}{l}+T_{f 0}, \quad 0 \leq x \leq l$

Where $T_{f 0}$ is the foot sole temperature in the static steady condition. Hence, the dissipated heat flux from the foot sole is:

$q_{m e t 0}^{\prime \prime}=k_{s} \frac{T_{f 0}-T_{G}}{l}$

Since, the body is in thermal equilibrium, therefore, $q_{m e t 0}^{\prime \prime}$ is heat flux that is dissipated from the foot sole.

\subsection{Foot temperature prediction of a person who starts Walking/jogging from the standstill condition}

As the second studied scenario, the person starts walking/jogging at different speeds from standstill condition. The process of walking and jogging is presented in Fig. 1. Moreover, the following assumptions are considered:

- The ground and ambient temperature are assumed to be constant.

- It is assumed that during the walking/jogging activity, the foot sole is always in contact with the inner surface of the shoe sole and that the sole of foot and top inner surface of 
the shoe sole have the same temperature. Therefore, there is no air gap between the foot sole and inner surface of the shoe sole (i.e. no convective heat transfer).

- During the walking/jogging, as shown in Fig. 1b, the shoe sole, is mainly cooled by convection of air $\left(q_{\text {conv }}^{\prime \prime}\right)$.

- The heat transfer problem of this scenario is a transient problem in which the person starts walking and jogging from standstill position and then goes to the recovery phase. Therefore to predict the foot temperature in shoe the foot temperature during standstill is required as an initial solution for standstill condition (Eq. (7))

- $\quad$ Foot with no socks are considered in the shoe.

Based on the above discussion a transient conductive heat transfer equation governs as follow (Hahn and Özisik, 2012):

$k_{s} \frac{d^{2} T}{d x^{2}}+q_{G e n}^{\prime \prime \prime}=\rho_{s} c_{p s} \frac{d T}{d \tau}$

where, $\rho_{s}$ and $c_{p s}$ are shoe sole density and specific heat properties, respectively. $q_{G e n}^{\prime \prime \prime}$ is the average heat generation rate per unit volume of the shoe sole due to viscous work in a time period (Sec. 2.3).

By assuming, the person has initiated the exercise from standstill condition (Sec. 2.2.1), the initial condition of Eq. (9) is a linear temperature distribution as presented in Eq. (7), i.e.:

$T(x, \tau=0)=\left(T_{\infty}-T_{f 0}\right) \frac{x}{l}+T_{f 0}, \quad 0 \leq x \leq l$

The boundary conditions at the inner surface of the shoe sole and the outer surface of the shoe sole respectively are:

$$
\begin{aligned}
& {\left[q_{m e t}^{\prime \prime}(\tau)=-k_{s} \frac{d T}{d x}\right]_{x=0}} \\
& {\left[h\left(T-T_{\infty}\right)=-k_{s} \frac{d T}{d x}\right]_{x=l}}
\end{aligned}
$$


where, as discussed earlier, $q_{m e t}^{\prime \prime}$ and $h$ are the metabolism heat flux as a function of time and convective heat transfer coefficient, respectively. Methods of estimation of these parameters were presented in Sec. 2.2 and Sec. 2.4.

The aforementioned governing equations, initial condition, and boundary conditions can be non-dimensionalized by the following transformation:

$$
\hat{x}=\frac{x}{l}, \hat{t}=\frac{\alpha_{s} \cdot \tau}{l^{2}}, \hat{Q}_{g e n}=\frac{l^{2} \cdot q_{G e n}^{\prime \prime \prime}}{k_{S}\left(T_{f 0}-T_{\infty}\right)}, \hat{Q}_{m e t}=\frac{l \cdot q_{m e t}^{\prime \prime}}{k_{S}\left(T_{f 0}-T_{\infty}\right)}, B i=\frac{h \cdot l}{k_{s}}, \theta=\frac{T-T_{\infty}}{T_{f 0}-T_{\infty}}
$$

where $\alpha_{s}=\frac{k_{s}}{\rho_{s} \cdot c p_{s}}$. Therefore, Eq. (9) and Eqs. (10) to (12) are converted to:

$\frac{d^{2} \theta}{d \hat{x}^{2}}+\hat{Q}_{g e n}=\frac{d \theta}{d \hat{t}}$

$\theta(\hat{x}, \hat{t}=0)=-\hat{x}+1, \quad 0 \leq \hat{x} \leq 1$

$\left[\widehat{Q}_{m e t}(\hat{t})=-\frac{d \theta}{d \hat{x}}\right]_{\hat{x}=0}$

$\left[\frac{d \theta}{d \hat{x}}+B i \cdot \theta\right]_{\hat{x}=1}=0$

The solution of Eq. (13) is (please refer to Appendix 1):

$\theta(\hat{x}, \hat{t})= \begin{cases}\theta_{1}(\hat{x}, \hat{t}) & \text { if } \quad \hat{t}<\hat{t}_{1} \\ \theta_{2}(\hat{x}, \hat{t}) & \text { if } \quad \hat{t} \geq \hat{t}_{1}\end{cases}$

and,

$\theta_{1}(\hat{x}, \hat{t})=\frac{\hat{Q}_{g e n}}{2}\left[\frac{2+B i}{B i}-\hat{x}^{2}\right]+F \cdot \hat{Q}_{m e t 0}\left[\frac{1+B i}{B i}-\hat{x}\right]+\sum_{n} B_{n} \cos \left(\lambda_{n} \hat{x}\right) e^{-\lambda_{n}^{2} \hat{t}}$

$\theta_{2}(\hat{x}, \hat{t})=\frac{\hat{Q}_{g e n}}{2}\left[\frac{2+B i}{B i}-\hat{x}^{2}\right]+\hat{Q}_{m e t 0}\left[\frac{1+B i}{B i}-\hat{x}\right]+\sum_{n} C_{n} \cos \left(\lambda_{n} \hat{x}\right) e^{-\lambda_{n}^{2}\left(\hat{t}-\hat{t}_{1}\right)}$

Moreover:

$$
B_{n}=\frac{-\left[\frac{\hat{Q}_{g e n}+F \cdot \hat{Q}_{m e t 0}}{B i \cdot \lambda_{n}}+\frac{\hat{Q}_{g e n}}{\lambda_{n}^{3}}\right] \sin \left(\lambda_{n}\right)+\left[\frac{\hat{Q}_{g e n}+F \cdot \hat{Q}_{m e t 0}-1}{\lambda_{n}^{2}}\right] \cos \left(\lambda_{n}\right)-\left[\frac{F \cdot \hat{Q}_{m e t 0}-1}{\lambda_{n}^{2}}\right]}{\frac{\sin \left(2 \lambda_{n}\right)+2 \lambda_{n}}{4 \lambda_{n}}}
$$


$C_{n}=B_{n} e^{-\lambda_{n}^{2} \cdot \hat{t}_{1}}+\frac{\hat{Q}_{m e t 0}(F-1)\left[1-\cos \left(\lambda_{n}\right)+\frac{\lambda_{n} \sin \left(\lambda_{n}\right)}{B i}\right]}{\frac{\sin \left(2 \lambda_{n}\right)+2 \lambda_{n}}{4} \lambda_{n}}$

This series solution converges fast with a maximum of six first terms. However, what is the most important is foot sole temperature or $\theta(\hat{x}=0, \hat{t})$ for which, Eqs (18) and (19) are reduced to:

$\theta_{1}(\hat{x}, \hat{t})=\frac{\hat{Q}_{g e n}}{2}\left[\frac{2+B i}{B i}\right]+F \cdot \hat{Q}_{m e t 0}\left[\frac{1+B i}{B i}\right]+\sum_{n} B_{n} e^{-\lambda_{n}^{2} \hat{t}}$

$\theta_{2}(\hat{x}, \hat{t})=\frac{\hat{Q}_{g e n}}{2}\left[\frac{2+B i}{B i}\right]+\hat{Q}_{m e t 0}\left[\frac{1+B i}{B i}\right]+\sum_{n} C_{n} e^{-\lambda_{n}^{2}\left(\hat{t}-\hat{t}_{1}\right)}$

These are practical equations that can be calculated even with a simple engineering calculator. (For $\lambda_{n}$, please refer to Appendix 1).

\section{Results:}

To verify the derived equations, the experimental results of Shimazaki et al. (Shimazaki et al., 2016) are utilized for validation. In those experiments, Shimazaki et al. (Shimazaki et al., 2016) examined the effect of gait speed and wear fitting on the foot temperature. For this reason, they measured foot sole temperature inside a shoe at different points. The participants were seven healthy adult males $(1.72 \pm 0.07 \mathrm{~m}$ height, $61.8 \pm 4.7 \mathrm{~kg}$ weight, and $23.8 \pm 4.3$ years old). The footwear with a mesh upper was a running shoe. Fig. 5 displays the utilized shoe in their experiments. In this study, the foot sole length is $L=25 \mathrm{~cm}(1 \mathrm{~cm}$ less than the shoe sole length due to shoe thickness) and the experiments were performed at $25{ }^{\circ} \mathrm{C}$ with no solar radiation. 


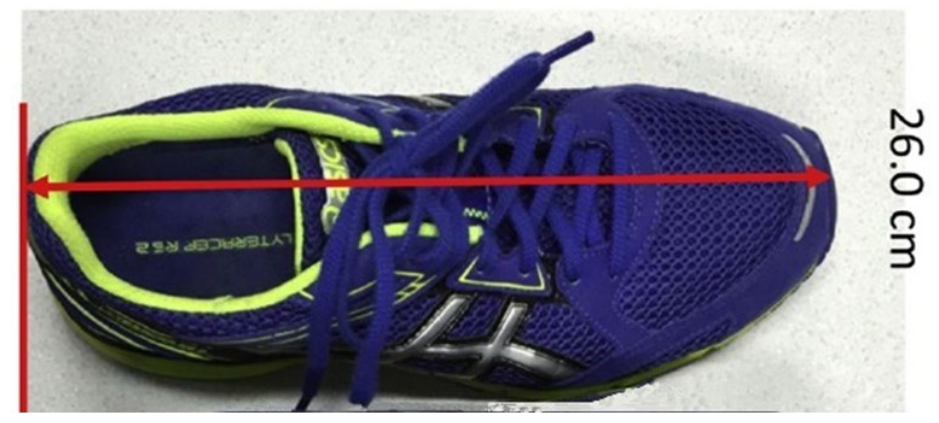

Fig. 5: The footwear used in experiment (Shimazaki et al., 2016)

The experiments performed for four different gait speed, i.e. 3, 6, 9, and $12 \mathrm{~km} / \mathrm{hr}$ (Shimazaki et al., 2016). Measured mean foot temperature at plantar arch and ball in the first three speeds were selected for validation. The shoe sole is EVA08 and its thermal properties are presented in Table 2 (Shimazaki and Aisaka, 2018).

Table 2: Shoe sole thermal-mechanical properties (Shimazaki and Aisaka, 2018)

\begin{tabular}{lcccccc}
\hline Material & $\begin{array}{c}c_{p s} \\
\left(\mathrm{~J} \cdot \mathrm{kg}^{-1} \cdot \mathrm{K}^{-1}\right)\end{array}$ & $\begin{array}{c}k_{s} \\
\left(\mathrm{~W} \cdot \mathrm{m}^{-1} \cdot \mathrm{K}^{-1}\right)\end{array}$ & $\begin{array}{c}\rho_{s} \\
\left(\mathrm{~kg} \cdot \mathrm{m}^{-3}\right)\end{array}$ & $\begin{array}{c}E^{\prime \prime} \\
(\mathrm{Pa})\end{array}$ & $\begin{array}{c}E^{\prime} \\
(\mathrm{Pa})\end{array}$ & Hardness \\
\hline EVA08 & 2585 & 0.11 & 240 & $1.55 \mathrm{E}+6$ & $12.6 \mathrm{E}+6$ & A45 \\
EVA12 & 2441 & 0.12 & 170 & $1.01 \mathrm{E}+6$ & $7.56 \mathrm{E}+6$ & A35 \\
\hline
\end{tabular}

Also, air thermo-physical properties are presented in Table 3.

Table 3: Air thermo-physical properties at $25^{\circ} \mathrm{C}$ (Bergman et al., 2011)

\begin{tabular}{ccccc}
\hline Material & $c_{\mathrm{p}}$ & $k$ & $\rho$ & $\mu$ \\
& $\left(\mathrm{J} . \mathrm{kg}^{-1} \cdot \mathrm{K}^{-1}\right)$ & $\left(\mathrm{W} . \mathrm{m}^{-1} \cdot \mathrm{K}^{-1}\right)$ & $\left(\mathrm{kg} . \mathrm{m}^{-3}\right)$ & $($ Pa.s $)$ \\
\hline Air & 1006.96 & 0.0261 & 1.171 & $1.84 \mathrm{E}-5$ \\
\hline
\end{tabular}


The factor of increase in metabolism rate $(F)$ for different gait speeds is adopted from the experimental correlation of Kipp (Kipp, 2017). In this regard, $F$ is:

$F(V)=1.3 \frac{0.009 V^{2}+0.002 V+0.082}{0.009 V_{\text {ref }}^{2}+0.002 V_{\text {ref }}+0.082}$

$V_{\text {ref }}$ is $0.833 \mathrm{~m} / \mathrm{s}$ or $3 \mathrm{~km} / \mathrm{hr}$ equivalently. $\sigma_{0}$ is calculated by dividing the maximum contact force by the average contact area reported (Shimazaki and Murata, 2015). The average contact area is $0.006 \mathrm{~m}^{2}$ and the used maximum contact force for each velocity is listed in Table 1. Intermediate output results for gait speed $3 \mathrm{~km} / \mathrm{hr}$ are presented in Appendix 2 as a guide.

For validation, the average foot sole temperature raise for each speed were calculated and compared with experimental measurements for foot (Shimazaki et al., 2016) are presented in Fig. 6.

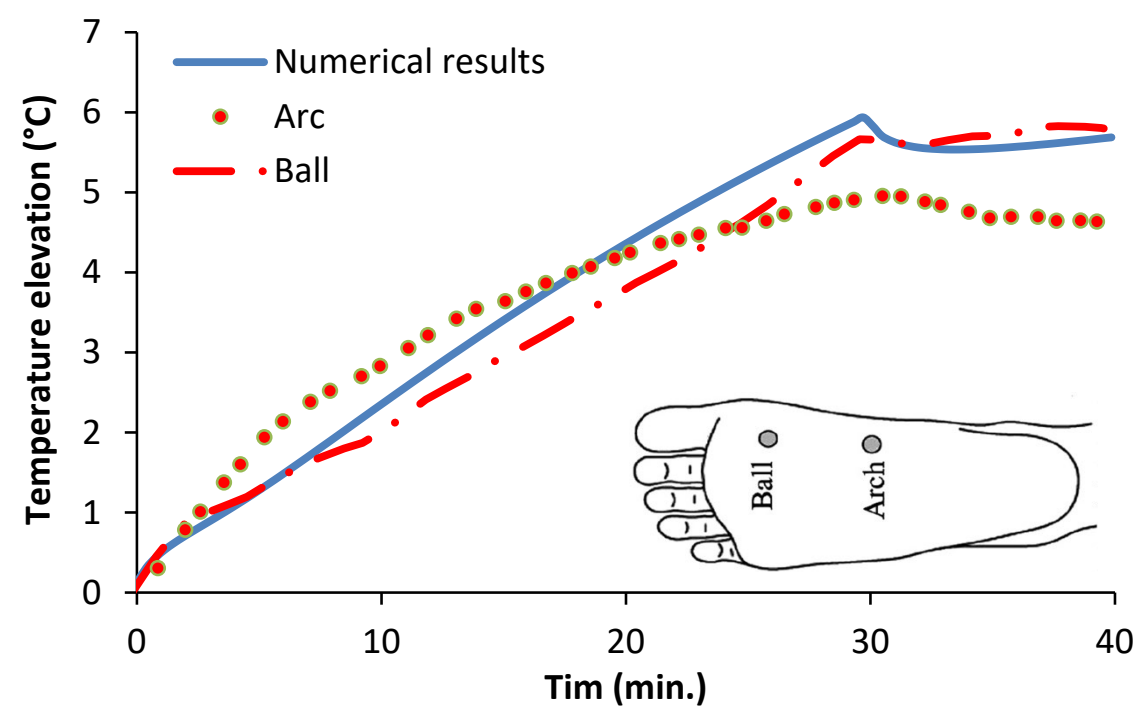

a) Gait speed $3 \mathrm{~km} / \mathrm{hr}$ 


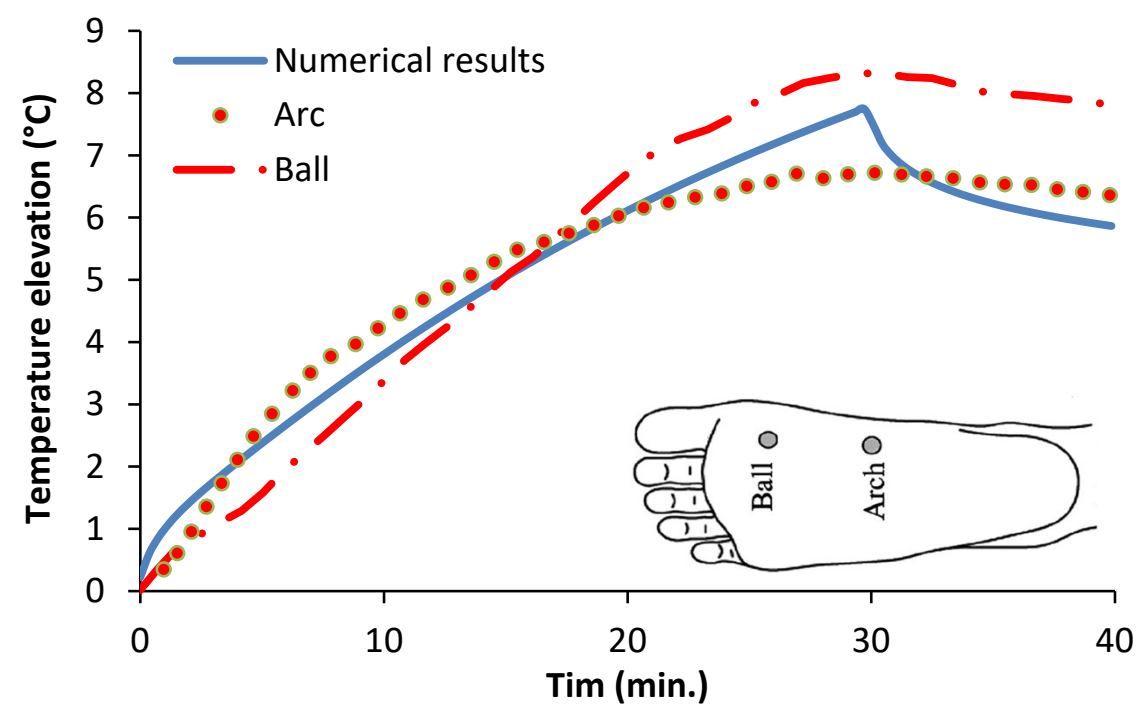

b) Gait speed $6 \mathrm{~km} / \mathrm{hr}$

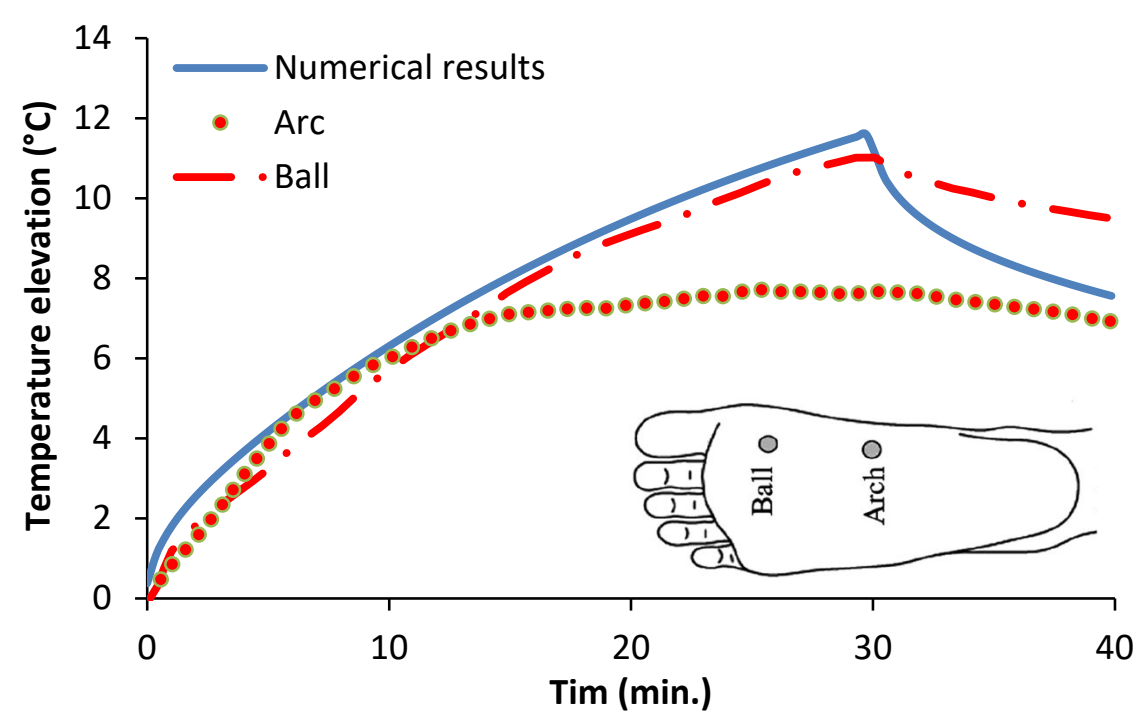

c) Gait speed $9 \mathrm{~km} / \mathrm{hr}$

Fig. 6: Comparison of foot sole temperature based on numerical simulation and experimental measurements (Shimazaki et al., 2016)

A good agreement can be observed between experimental and numerical results (Fig. 6). The RSME (Root Squared Error) between predicted values and measured values for the first 30 minutes and the second 10 minutes at different gait speed are presented in Table 4. 
Table 4: RMSE between predicted values and measured values

\begin{tabular}{|c|c|c|c|c|}
\hline Gait Speed & & $3 \mathrm{~km} / \mathrm{hr}$ & $6 \mathrm{~km} / \mathrm{hr}$ & $9 \mathrm{~km} / \mathrm{hr}$ \\
\hline RMSE for & $0-30 \mathrm{~min}$. & 0.4 & 0.58 & 0.58 \\
\hline Ball Part & & & & \\
\hline$\left[{ }^{\circ} \mathrm{C}\right]$ & $30-40 \mathrm{~min}$. & 0.16 & 1.75 & 1.45 \\
\hline RMSE for & $0-30 \mathrm{~min}$. & 0.49 & 0.46 & 1.92 \\
\hline Arch Part & & & & \\
\hline$\left[{ }^{\circ} \mathrm{C}\right]$ & 30-40 min. & 0.87 & 0.41 & 1.68 \\
\hline
\end{tabular}

The RMSE between two curves in the range $\left[\tau_{1}, \tau_{2}\right]$ is defined as (Bird, 2017):

$\operatorname{RMSE}=\left[\frac{\int_{\tau_{1}}^{\tau_{2}}\left(T_{\text {Predict }}(\tau)-T_{\text {Measured }}(\tau)\right)^{2} d \tau}{\tau_{2}-\tau_{1}}\right]^{\frac{1}{2}}$

where $T_{\text {Predict }}$ and $T_{\text {Measured }}$ are predicted and measured temperatures at time $\tau$, respectively.

As shown in this figure, for gait speed $3 \mathrm{~km} / \mathrm{hr}$, foot sole experiences $6^{\circ} \mathrm{C}$ increase in temperature while at $6 \mathrm{~km} / \mathrm{hr}$ and $9 \mathrm{~km} / \mathrm{hr}$, temperatures increases reaches $8^{\circ} \mathrm{C}$ and $11.5^{\circ} \mathrm{C}$, respectively. In high gait speed ( $9 \mathrm{~km} / \mathrm{hr})$, RMSE shows that the numerical results are closer to the experimental values for foot temperature at the ball of the foot compared to the arch region. This phenomenon can be attributed to convective heat transfer that more dominantly affects the arch area (compared to the ball of the foot) as a result of the air-filled gap between the flat insole and the sole of the foot. Indeed, for longer times (more than 15 minutes), the sweating mechanism with the aid of convection will play role in cooling the arch area and therefore, conduction cannot be considered as the only dominant heat transfer mode. Since convection has not been considered in this study, the less satisfactory results for predicting temperature at the arch compared to the ball of the foot was expected. 
It can also be observed that there is a relatively sharp temperature drop in numerical simulation in comparison to experimental measurements. Shimazaki and Murata (Shimazaki and Murata, 2015) claimed that after 30 minutes of jogging, the metabolism rate immediately returns to its original value. However, comparing numerical results with experimental data reveals that this scenario may be only accurate for low speed, $3 \mathrm{~km} / \mathrm{hr}$. For higher velocities, as shown in Figure 3, it seems that the metabolism rate returns to a slightly higher level than the reported value for the original state.

To show the applicability of the results in the footwear industry, as a complementary study, we considered using a softer shoe sole material (EVA12) for different speeds. The comparison of the shoe with the sole made of EVA08 and EVA12 is presented in Fig. 7 at two different gait speeds. As it was concluded from Appendix 2, $\hat{Q}_{g e n}$ is negligible in comparison to $\hat{Q}_{m e t}$. So, stiffness of shoe sole does not seem to affect the foot temperature elevation. However, as shown in Fig. 7, the maximum temperature rise for EVA12 is $3^{\circ} \mathrm{C}$ higher than EVA08. This shows that although EVA12 is softer and maybe more comfortable, the shoe with a sole made of EVA08 has thermally more suitable than EVA12. 


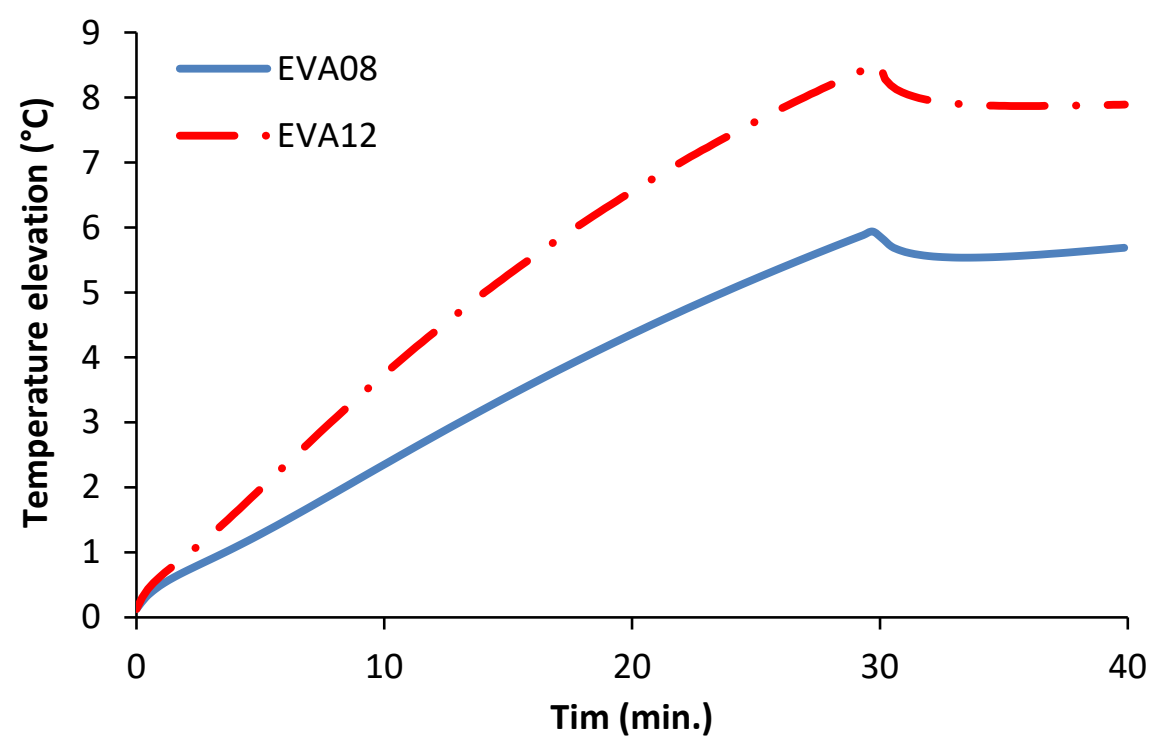

a) Gait speed $3 \mathrm{~km} / \mathrm{hr}$

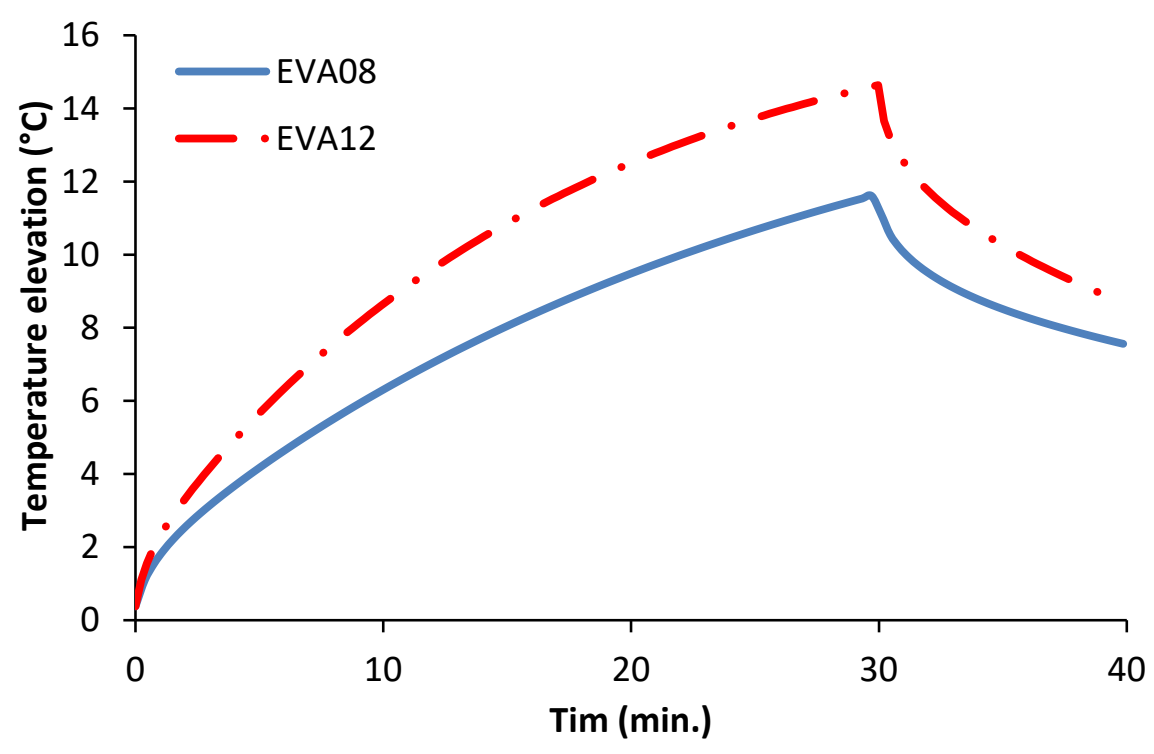

b) Gait speed $6 \mathrm{~km} / \mathrm{hr}$

Fig. 7: Comparison of EVA08 and EVA12 as shoe sole for two different speeds, thermally.

Study of Eq. (16) shows that since the thermal conductivity of both materials are in the same range, $B i$ and $\lambda_{n}$ do not differ significantly. So, the main reason for the higher temperature for the shoe sole made of EVA12 is the dimensionless time $\hat{t}$ or explicitly, the factor $\rho_{s} c_{p s}$ (thermal capacity). As for a specified value of heat flux, the material with lower thermal capacity has higher temperature elevation. The thermal capacity of EVA12 is $50 \%$ higher 
than EVA08. This means that to prevent the shoe from heating up, the possibility of airflow in the shoe and cooling the foot by air convection inside the shoe shall be considered in the design of footwear with shoe sole of EVA12.

\section{Discussion}

In this study, the foot sole temperature in a shoe was studied mathematically. The solution of governing equations was presented as a simple practical formula. This formula can be used as an efficient tool to predict the temperature at the foot sole in the shoe. So, before any time consuming and costly experiment, effective parameters as well as possible results can be investigated. In this study, it was shown that in addition to thermal conductivity, heat capacity of the shoe sole plays an important role in controlling the foot sole temperature rise. Heat capacity is an index that indicates the potential of storing heat in a material for a fixed value of temperature elevation. On one hand, increasing thermal conductivity decreases the dimensionless heat flux $\left(\hat{Q}_{\text {meto }}\right)$ that causes a decrease in temperature elevation and on the other hand, decreasing the heat capacity $\left(\rho_{s} c_{p s}\right)$ also increases the temperature elevation. However, footwear sole materials usually have low thermal conductivity. So, for activities of short duration, the higher value of heat capacity (which shows the potential of heat absorption with small temperature rise) is thermally beneficial. Based on the above explanation, in using EAV12 with higher thermal diffusivity as shoe sole, every effort shall be made to increase the convection contribution.

The contribution of different phenomena can be distinct by mathematical simulation. As an example, it was shown that the temperature variation in time during the simulation period was to a large extent, adopted to the ball of the foot which shows that conduction can be the governing heat transfer mode in that part of the foot. However, the arch temperature deviates slightly beyond 15 minutes. 
In the proposed solution, the air convection inside the shoe, shoe ventilation, transpiration, or any other related cooling mechanism was not considered. In fact, heat conduction was the only mode of heat transfer from the sole of the foot to the shoe sole. However, it was shown that the experimentally measured temperature of the foot arch and ball of the foot show different trends after a time. Comparing the first 30 minutes during the jogging for experimental and analytical results shows that the temperature measured at the ball of the foot is comparable to the temperatures calculated using analytical solution. But, the temperature at the foot arch deviated slightly after about 10 to 15 minutes from the start of jogging. The close proximity between the measured temperature with the calculated temperature (using the analytical solution) at the arch of the foot in walking $(3 \mathrm{~km} / \mathrm{h})$, start deviating after $17 \mathrm{~min}$. This can indicate that the effect of other types of heat transfer i.e. convection over foot arch is negligible for up to $17 \mathrm{~min}$. However, during jogging i.e. at higher speed $(9 \mathrm{~km} / \mathrm{h})$, the measured and calculated temperatures at the foot arch start deviating after only $10 \mathrm{~min}$ that can be related to higher transpiration and higher airflow rate into the shoe at higher speeds.

The other remark is the degree of importance of heating sources, i.e. of $\widehat{Q}_{m e t}$ and $\hat{Q}_{g e n}$. It was shown that for EVA group material, $\hat{Q}_{g e n}$ can be easily ignored beside the $\hat{Q}_{m e t}$. In other words, the mechanical properties of EVA materials do not seem to influence their thermal behaviour. Under this condition, Eqs. (26) to (29) can even reduce further to the following simpler forms by eliminating $\hat{Q}_{g e n}$ :

$$
\begin{aligned}
B_{n} & =\frac{-\frac{F \cdot \hat{Q}_{m e t 0}}{B i \cdot \lambda_{n}} \sin \left(\lambda_{n}\right)+\left[\frac{F \cdot \hat{Q}_{m e t 0}-1}{\lambda_{n}^{2}}\right] \cos \left(\lambda_{n}\right)-\left[\frac{F \cdot \hat{Q}_{m e t 0}-1}{\lambda_{n}^{2}}\right]}{\frac{\sin \left(2 \lambda_{n}\right)+2 \lambda_{n}}{4 \lambda_{n}}} \\
C_{n} & =B_{n} e^{-\lambda_{n}^{2} \cdot \hat{t}_{1}}+\frac{\hat{Q}_{m e t 0}(F-1)\left[1-\cos \left(\lambda_{n}\right)+\frac{\lambda_{n} \sin \left(\lambda_{n}\right)}{B i}\right]}{\frac{\sin \left(2 \lambda_{n}\right)+2 \lambda_{n}}{4} \lambda_{n}}
\end{aligned}
$$




$$
\begin{aligned}
& \theta_{1}(\hat{x}, \hat{t})=F . \hat{Q}_{\text {met } 0}\left[\frac{1+B i}{B i}\right]+\sum_{n} B_{n} e^{-\lambda_{n}^{2} \hat{t}} \\
& \theta_{2}(\hat{x}, \hat{t})=\hat{Q}_{\text {met } 0}\left[\frac{1+B i}{B i}\right]+\sum_{n} C_{n} e^{-\lambda_{n}^{2}\left(\hat{t}-\hat{t}_{1}\right)}
\end{aligned}
$$

In this study, we showed that the analytical method can provide a quick and reliable estimation of foot temperature. The proposed method as a design tool has advantages over the numerical (Finite Element Analyses) and experimental investigations as it is less time consuming and less expensive. The prediction of in-shoe temperature with the proposed analytical method can be useful in designing footwear for walking with appropriate thermal characteristics for people with diabetes as soft tissue can be more prone to ulceration at higher temperatures (Ersen et al., 2018; Houghton et al., 2013). In other words, the mathematical method can provide a tool to predict the foot temperature in a shoe at the design stage and before manufacturing within a reasonable accuracy

\section{Conclusions}

It is known that wearing inappropriate footwear during with load-bearing activity can lead to high plantar tissue temperatures and consequently increases the risk of trauma to the foot. However, the design of footwear with appropriate properties is not straightforward, because the effective thermo-mechanical parameters and the way that they affect the thermal characteristics of the foot are not clear. Hence, it was not possible to have a primary estimation of plantar tissue temperature in shod condition before the design and manufacture of the footwear and after a large number of experiments.

In this study, we solved the governing heat transfer equation analytically and presented a practical formula that enables the prediction of the foot sole temperature during walking. The presented formula of this study was validated against experimentally measured data at 
different walking and jogging speeds. Very good agreements were observed between results and measured data, even at running speed as high as $9 \mathrm{~km} / \mathrm{hr}$.

To the best of the authors' knowledge, this is the first time that both mechanical and thermal properties of shoe sole are considered in the prediction of heat loss from the shoe. The effect of different thermal properties such as heat capacity, heat diffusivity, and thermal conductivity in addition to the mechanical properties were clarified. It was shown that heat capacity of the shoe sole can considerably reduce the temperature increase in the short term and it can be even more effective than thermal conductivity. Moreover, it can be concluded that for the specific shoe under the study, the heat transfer mode for the ball part is purely conduction, while other mechanisms such as the airflow with the aid of transpiration augments the cooling of the foot arch part for at the higher speed $(V=9 \mathrm{~km} / \mathrm{hr})$.

Two different shoe sole materials (EVA08 and EVA12) were compared thermally to show the applicability of the findings. The developed tool upon further experimental validation offers potentials to provide good estimation of the footwear thermal comfort without the need for having access to large physical and computational resources 


\section{Nomenclature}

A

$B_{n}$

$B i=\frac{h . l}{k_{s}}$

$c_{p}$

$C_{n}$

$E^{\prime}$

$E^{\prime \prime}$

F

$h$

$k$

$L$

$\operatorname{Pr}=\frac{\mu \cdot c p}{k}$

$\hat{Q}$

$q^{\prime \prime}$

$q^{\prime \prime \prime}$

$R e=\frac{\rho \cdot V \cdot L}{\mu}$

$T$

$l$

$\hat{t}=\frac{\alpha_{s} \cdot \tau}{l^{2}}$

$U_{d}$

V

$x$

$\hat{x}=\frac{x}{l}$
Area

Constant coefficient

Biot number

Specific heat

Constant coefficient

Storage modulus

Loss modulus

Metabolism rate increase factor

Average convective heat transfer coefficient

Thermal conductivity

Shoe length

Prandtl number

Dimensionless heat

Heat flux

Volumetric heat generation power

Reynolds number

Temperature

Thickness

Dimensionless time

Dissipated energy per unit of volume in one period

Gait speed

Cartesian coordinate axis

Dimensionless coordinate axis 
Greek letters

$\begin{array}{ll}\varepsilon_{0} & \text { Strain amplitude } \\ \lambda_{n} & \text { Eigenvalue, Solution of } \lambda_{n} \tan \left(\lambda_{n}\right)=B i \\ \mu & \text { Viscosity } \\ \theta=\frac{T-T_{\infty}}{T_{f 0}-T_{\infty}} & \text { Dimensionless temperature difference } \\ \rho & \text { Density } \\ \sigma_{0} & \text { Stress amplitude } \\ \tau & \text { time }\end{array}$

Subscripts

$\begin{array}{ll}\text { cont } & \text { Contact } \\ \text { conv } & \text { Convection } \\ f 0 & \text { Foot sole in the static steady condition } \\ f & \text { Foot sole in the jogging condition } \\ G & \text { Ground } \\ \text { gen } & \text { Generation } \\ \text { met } & \text { metabolism } \\ \mathrm{s} & \text { Shoe sole } \\ \infty & \text { Ambient }\end{array}$




\section{Appendix 1}

Eq. (13) is a second-order partial differential equation that can be solved by separation of variables method (Hahn and Özisik, 2012). A part of the solution can be presented as the equilibrium solution $\left(u_{E}(\hat{x})\right)$. So, the total solution is:

$\theta(\hat{x}, \hat{t})=u_{E}(\hat{x})+v(\hat{x}, \hat{t})$

$u_{E}(\hat{x})$ shall satisfy the following equation with the following boundary conditions:

$\frac{d^{2} u_{E}(\hat{x})}{d \hat{x}^{2}}+\hat{Q}_{g e n}=0$

$\left[\hat{Q}_{m e t}(\hat{t})=-\frac{d u_{E}(\hat{x})}{d \hat{x}}\right]_{\hat{x}=0}$

$\left[\frac{d u_{E}(\hat{x})}{d \hat{x}}+B i \cdot u_{E}(\hat{x})\right]_{\hat{x}=1}=0$

$\left[0=-\frac{d v(\hat{x}, \hat{t})}{d \hat{x}}\right]_{\hat{x}=0}$

$\left[\frac{d v(\hat{x}, \hat{t})}{d \hat{x}}+B i \cdot \theta\right]_{\hat{x}=1}=0$

The solution of Eq. (A2) is:

$\theta(\hat{x}, \hat{t})=\frac{\hat{Q}_{g e n}}{2}\left[\frac{2+B i}{B i}-\hat{x}^{2}\right]+F \cdot \hat{Q}_{m e t 0}\left[\frac{1+B i}{B i}-\hat{x}\right]$

and the solution of Eq. (A3) has the form of:

$v(\hat{x}, \hat{t})=\sum_{n} B_{n} \cos \left(\lambda_{n} \hat{x}\right) e^{-\lambda_{n}^{2} \hat{t}}$

$\lambda_{n}$ is the solution of: 
$\lambda_{n} \tan \left(\lambda_{n}\right)=B i$

The following equations can be proposed by authors to estimate the first six solutions with maximum error, less than $0.47 \%$ :

$\lambda_{0}=\frac{\pi}{2}-\frac{\pi / 2-B i^{0.5}}{1-0.1976 B i^{1.796}}$

$\lambda_{1}=\frac{3 \pi}{2}-\frac{\pi / 2-0.0011 B i}{1+0.223 B i^{1.107}}$

$\lambda_{2}=\frac{5 \pi}{2}-\frac{\pi / 2}{1+0.1066 B i^{1.145}}$

$\lambda_{3}=\frac{7 \pi}{2}-\frac{\pi / 2}{1+0.0664 B i^{1.166}}$

$\lambda_{4}=\frac{9 \pi}{2}-\frac{\pi / 2}{1+0.0468 B i^{1.181}}$

$\lambda_{5}=\frac{11 \pi}{2}-\frac{\pi / 2}{1+0.0355 B i^{1.201}}$

For $\hat{t} \geq \hat{t}_{1}$ the above method is still applicable. However, the initial condition must be replaced by the solution of the first step at $\hat{t}=\hat{t}_{1}$. 


\section{Appendix 2}

\begin{tabular}{|c|c|c|c|c|c|}
\hline \multicolumn{6}{|c|}{ Input Parameters } \\
\hline \multicolumn{6}{|c|}{ Air Specifications } \\
\hline$T_{\infty}\left({ }^{\circ} \mathrm{C}\right)$ & $\rho(\mathrm{kg} / \mathrm{m} 3)$ & $k(\mathrm{~W} / \mathrm{mK})$ & $c p(\mathrm{~J} / \mathrm{kgK})$ & $\mu(\mathrm{Pa} . \mathrm{s})$ & \\
\hline 25 & 1.171 & 0.0261 & 1006.96 & $1.84 \times 10^{-5}$ & \\
\hline \multicolumn{6}{|c|}{ Shoe Sole Specifications } \\
\hline$\rho_{s}(\mathrm{~kg} / \mathrm{m} 3)$ & $k_{s}(\mathrm{~W} / \mathrm{mK})$ & $c p_{s}(\mathrm{~J} / \mathrm{kg} . \mathrm{K})$ & $E^{\prime \prime}(\mathrm{Pa})$ & $E^{\prime}(\mathrm{Pa})$ & \\
\hline 240 & 0.11 & 2585 & $1.55 \times 10^{6}$ & $12.16 \times 10^{6}$ & \\
\hline \multicolumn{6}{|c|}{ Geometric Parameters } \\
\hline$A_{\text {cont }}\left(\mathrm{m}^{2}\right)$ & $A\left(\mathrm{~m}^{2}\right)$ & $L(\mathrm{~m})$ & $t(\mathrm{~m})$ & & \\
\hline 0.006 & 0.018 & 0.25 & 0.02 & & \\
\hline \multicolumn{6}{|c|}{ General Parameters } \\
\hline$t_{\text {Stance }}(\mathrm{s})$ & $t_{\text {Swing }}(\mathrm{s})$ & Weight $(\mathrm{kg})$ & & & \\
\hline 1 & 0.5 & 60 & & & \\
\hline \multicolumn{6}{|c|}{ Output Parameters } \\
\hline$R e$ & $P r$ & $h\left(\mathrm{~W} / \mathrm{m}^{2} . \mathrm{K}\right)$ & $q_{m e t 0}^{\prime \prime}\left(\mathrm{W} / \mathrm{m}^{2}\right)$ & $q_{G e n}^{\prime \prime \prime}$ & \\
\hline 13280 & 0.707 & 6.856 & 49.5 & 34.766 & \\
\hline$B i$ & $F$ & $\hat{t}_{1}$ & $\hat{Q}_{m e t}(\mathrm{~K})$ & $\hat{Q}_{g e n}(\mathrm{~K})$ & \\
\hline 1.247 & 1.3 & 0.798 & 1.3 & 0.014 & \\
\hline$\lambda_{0}$ & $\lambda_{1}$ & $\lambda_{2}$ & $\lambda_{3}$ & $\lambda_{4}$ & $\lambda_{5}$ \\
\hline 0.9299 & 3.4851 & 6.4734 & 9.5545 & 12.6645 & 15.7868 \\
\hline$B_{0}$ & $B_{1}$ & $B_{2}$ & $B_{3}$ & $B_{4}$ & $B_{5}$ \\
\hline
\end{tabular}




\begin{tabular}{|c|c|c|c|c|c|}
\hline \multicolumn{7}{|c}{0.873} & -0.535 & 0.135 & -0.144 & 0.05 \\
\hline$C_{0}$ & $C_{1}$ & $C_{2}$ & $C_{3}$ & $C_{4}$ & $C_{5}$ \\
-2.149 & 0.408 & 0.125 & 0.058 & 0.033 & 0.022 \\
\hline
\end{tabular}




\section{References}

Arezes, P., Neves, M.M., Teixeira, S., Leão, C.P., Cunha, J., 2013. Testing thermal comfort of trekking boots: An objective and subjective evaluation. Appl. Ergon 44, 557-565.

Bergman, T.L., Incropera, F.P., Lavine, A.S., DeWitt, D.P., 2011. Introduction to heat transfer. John Wiley \& Sons.

Bird, J., 2017. Engineering Mathematics, 8 ed.

Bulcao, C.F., Frank, S.M., Raja, S.N., Tran, K.M., Goldstein, D.S., 2000. Relative contribution of core and skin temperatures to thermal comfort in humans. Journal of Thermal Biology 25, 147-150.

Carbonell, L., Priego Quesada, J.I., Retorta, P., Benimeli, M., Cibrián Ortiz De Anda, R.M., Salvador Palmer, R., González Peña, R.J., Galindo, C., Pino Almero, L., Blasco, M.C., 2019. Thermographic quantitative variables for diabetic foot assessment: preliminary results. Comput. Method. Biomech. Biomed. Eng. Imaging Vis. 7, 660-666.

Chuckpaiwong, B., Nunley, J.A., Mall, N.A., Queen, R.M., 2008. The effect of foot type on in-shoe plantar pressure during walking and running. Gait Posture. 28, 405-411.

Covill, D., Guan, Z., Bailey, M., Pope, D., 2008. Finite element analysis of the heat transfer in footwear, The Engineering of Sport. Springer, pp. 247-254.

Covill, D., Guan, Z., Bailey, M., Raval, H., 2011. Development of thermal models of footwear using finite element analysis. P. I. Mech. Eng. H 225, 268-281.

Dessing, O., Jansen, A.J., Leihitu, C., Overhage, D., 2014. Experimental study of heat dissipation in indoor sports shoes, Procedia Engineering, 72, 2014; The 2014 Conference of the International Sports Engineering Association, Sheffield, UK, 14-17 July 2014. Elsevier.

Ersen, A., Adams, L.S., Myers, R.T., Hirschman, G.B., Lavery, L.A., Yavuz, M., 2018. Temperature Regulating Shoes for Prevention of Diabetic Foot Ulcers. Am Diabetes Assoc.

Hahn, D.W., Özisik, M.N., 2012. Heat conduction. John Wiley \& Sons.

Havenith, G., Gerrett, N., Faulkner, S., Ouzzahra, Y., Filingeri, D., 2013. Assessing the lower temperature limit for comfort in footwear. Proceedings of the 15th International Conference on Environmental Ergonomics, 238-239.

Houghton, V.J., Bower, V.M., Chant, D.C., 2013. Is an increase in skin temperature predictive of neuropathic foot ulceration in people with diabetes? A systematic review and meta-analysis. J. Foot Ankle. Res. 6, 31.

James, S., 1999. Encyclopaedia of Occupational Health and Safety 4th edition. Reference Reviews.

Kinoshita, H., Bates, B.T., 1996. The effect of environmental temperature on the properties of running shoes. J. Appl. Biomech. 12, 258-268.

Kipp, S., 2017. Why does metabolic rate increase curvilinearly with running velocity. MS thesis, University of Colorado, Boulder, Colo.

Kopitar, D., Akalovic, J., Skenderi, Z., 2019. Thermal resistance of leather and membranes for summer desert military footwear under different climate conditions, Functional Textiles and Clothing. Springer, pp. 3-9.

Kuklane, K., 2004. The use of footwear insulation values measured on a thermal foot model. Int. J. Occup. Saf. Ergo. 10, 79-86.

Mochon, S., McMahon, T.A., 1980. Ballistic walking: An improved model. Math. Biosci. 52, 241260.

Naemi, R., Chatzistergos, P.E., Chockalingam, N., 2016. A mathematical method for quantifying in vivo mechanical behaviour of heel pad under dynamic load. Med. Biol. Eng. Comput. 54, 341-350.

Naemi, R., Chockalingam, N., 2013a. Development of a method for quantifying the midsole reaction model parameters. Comput. Method. Biomec. 16, 1273-1277.

Naemi, R., Chockalingam, N., 2013b. Mathematical models to assess foot-ground interaction: an overview. Med. Sci. Sport. Exer. 45, 1524-1533. 
Puszkarz, A.K., Usupov, A., 2019. The Study of Footwear Thermal Insulation Using Thermography and the Finite Volume Method. Int. J. Thermophys. 40, 45.

Rebay, M., Arfaoui, A., Leopol, A., Perin, J., Taiar, R., 2007. Heat transfer in athletic shoes during the running, 5th IASME/WSEAS Int. Conference on Heat Transfer, Thermal Engineering and Environment, August 25-27, 2007. WSEAS Athens, Greece.

Rintamäki, H., Rissanen, S., Mäkinen, T., Peitso, A., 2004. Finger temperatures during military field training at 0 to -29 C. Journal of Thermal Biology 29, 857-860.

Schreurs, P., 2012. Material Models. Materials Technology.

Shimazaki, Y., Aisaka, K., 2018. Novel Thermal Analysis Model of the Foot-Shoe Sole Interface during Gait Motion, Multidisciplinary Digital Publishing Institute Proceedings, p. 278.

Shimazaki, Y., Matsutani, T., Satsumoto, Y., 2016. Evaluation of thermal formation and air ventilation inside footwear during gait: The role of gait and fitting. Appl. Ergon 55, 234-240.

Shimazaki, Y., Murata, M., 2015. Effect of gait on formation of thermal environment inside footwear. Appl. Ergon 49, 55-62.

Taiar, R., Rebay, M., Vannozzi, G., Sanna, G., Cappozzo, A., 2013. Evolution of the in-shoe temperature during walking and running. Proc. Biomed '08, Andreas Hierlemann ed., ACTA Press Anaheim, CA, USA, 130-133.

Taylor, N.A., Machado-Moreira, C.A., van den Heuvel, A.M., Caldwell, J.N., 2014. Hands and feet: physiological insulators, radiators and evaporators. Eur. J. Appl. Physiol. 114, 2037-2060. 